\title{
Breve panorama de la novela chilena reciente
}

Chile ha sido predominantemente un país de poetas. Por eso, no extraña que la prosa en general y la novela en particular no hayan recibido la debida atención. Francisco Santana, distinguido crítico chileno, en su excelente libro La mueva generación de prosistas chilenos, comenta: "Ante la potencialidad y brillo de nuestros poetas han quedado los prosistas al margen del reconocimiento que merecen". ${ }^{1}$

El presente trabajo tiene por objeto presentar, en forma breve, la producción de los novelistas más recientes de Chile. En 1940 un eminente crítico chileno, Pedro Nolasco Cruz, se expresó de manera muy pesimista sobre las perspectivas de la novela contemporánea en su patria. Escribió: "Por cierto nada tiene de brillante el cuadro de nuestra literatura novelesca... Lo peor es que, por ahora, no vemos indicios de que este género literario tome buena dirección." 2 Empero, durante la década que ha transcurrido desde aquella fecha, la situación ha cambiado radicalmente; en el Chile de hoy se manifiesta un nuevo y creciente interés en la novela que cuenta con un númeto imponente de cultivadores. En los párrafos siguientes indicaremos las figuras que más se destacan en el panorama novelístico chileno.

Un escritor típico de la época presente es Juan Godoy. Por el año de 1938 inició el "Angurrientismo", movimiento dedicado a la "intuición de la esencia chileno-cultural", y que atrajo a Fernando Alegría, Pedro de la Barra, Leoncio Guerrero y otros. Godoy escribió, en 1940, una novela titulada Angurrientos que había de servir como modelo y estímulo a los "angurrientistas". Consta de una se- 
rie de cuadros de la vida popular santiaguina. El autor se esfuerza por presentar a personajes típicamente chilenos, que nos deleitan con sus acciones graciosas y a veces picarescas. Su lenguaje sería a veces incomprensible para nosotros si no fuera por el glosario que aparece al fin del libro. Siguió a esta novela La cifra solitaria (1945), obra más breve y más imaginativa que escoge como escenario una región sureña. Interesan mucho tipos como el matarife Serafín y Golondrina el Ciego. Fiel a los principios del "Angurrientismo" el autor hace amplio uso de motivos folklóricos.

Escritor de tipo análogo es Leoncio Guerrero. Su novela $F a-$ luchos, publicada en 1946, presenta el pueblo de Constitución y describe minuciosamente las costumbres maulinas. Es una epopeya de la vida insegura y arriesgada de los habitantes del valle maulino $y$ de su incesante lucha contra el mar.

La zona salitrera del norte tiene a Andrés Sabella como su intérprete más fiel y más hábil. Su novela Norte grande (1944), subtitulada "Novela del salitre" está considerada por los chilenos como la mejor exposición literaria de aquella región, de su historia $\mathrm{y}$ sus tradiciones.

También Nicasio Tangol pertenece a la generación de jóvenes escritores que están tratando de explorar los valores genuinamente chilenos. 'Su primer libro, Huipampa (1944), subtitulado "Tierra de sonámbulos", describe las costumbres, supersticiones y leyendas de la región isleña de Chiloé. Dos mundos se entremezclan en la obra: el de las duras realidades de la existencia diaria y el mundo de fantasmas y terrores supersticiosos que prestan al libro in tinte de irrealidad y ensueño.

Se echa de ver que el regionalismo y el costumbrismo han sido cultivados con entusiasmo durante la última década. En cuanto a la novela campesina, el suceso de mayor resonancia fué la aparición de la obra Ránquil en 1942, escrita por Reinaldo Lomboy. En esta novela el autor se aparta de la tradición chilena que se limita a tratar el asunto "como si sobre el campo existiera una especie de consenso de respetar su apariencia idílica”, según observa Luis Alberto Sánchez. ${ }^{3}$ Ránquil constituye la epopeya de unos indios que colonizan una región árida del sur de Chile. Llega la orden de abandonar las tierras y los "hijueleros" emprenden una lucha sangrienta contra las fuerzas armadas, en la que casi todos perecen. 
La "novela de la tierra" (strbtítulo de la obra) interesa no solamente por su fuerza dramática sino también por la descripción auténtica y realista de la vida cotidiana de los colonos. Lomboy rinde tributo, a cada paso, al amor del colono indio por su tierra. Se nos presentan también paisajes de infinita belleza. La filosofía del libro puede resumirse en las palabras de uno de los personajes que después de sufrir un sinfín de desastres exclama: "Por mucho que puedan incendiar y matar, nunca podrán matar la tierra, porque no hay balas que le den muerte." " La crítica chilena ha alabado mucho la obra de Reinaldo Lomboy, verdadero jalón en las letras chilenas. Ránquil pertenece al ciclo latinoamericano de El Indio de López y Fuentes, El mundo es ancho y ajeno de Alegría, y Huasipungo de Icaza.

La segunda novela de Lomboy, titulada Ventarrón (1945), tiene por tema la intensa lucha que sostiene una comunidad de miseros pescadores-campesinos, para proporcionarse el pan cotidiano, en unas tierras arenosas, vapuleadas día y noche por los vientos del mar. E1 estilo de esta breve novela es más fino que el de Ránquil; pero la obra carece del drama humano y vibrante del primer libro.

La novela del mar, casi desconocida en Chile, tiene un intérprete en "Juan Negro" (pseudónimo del poeta Juan Agutirre). En Botella en el mar (1947) describe un puerto con sus gentes, esforzándose por poner de relieve todo lo que hay de legendario y misterioso en la vida marinera.

La novela humorística, igual que la novela del mar, ha tenido pocos cultivadores en Chile. Sin embargo, la presente generación cuenta con un escritor que ha acertado en este difícil género. Se trata de Enrique Araya cuya primera novela, La luna era mi tierra, recibió calurosa acogida en 1948. Narra en forma autobiográfica las experiencias tragicómicas de una joven que tropieza a cada paso con la desgracia y la desilusión.

Araya da otras pruebas de sus dotes de humorista y satírico en El caracol y la diosa (1950). El protagonista de este libro es un recluso de un manicomio que nos comunica sus memorias del año 20 , 912 y nos habla de sus encuentros con una extraña raza llamada los "S. 4". Estos seres, o más bien autómatas, son los descendientes. 
de la raza humana; pero todas sus funciones biológicas han sido reemplazadas por procesos mecánicos. Los "S. 4" llevan una vida regimentada en que todos los sentimientos humanos han desaparecido por completo y un grupo de gobernantes despóticos controlan cada acto de su existencia. Las charlas del protagonista con los "S. 4" proporcionan al autor amplias oportunidades de dar salida a su humorismo un tanto satírico. La novela nos recuerda la obra de Orwell, titulada 1984, que tan gran éxito tuvo recientemente en los Estados Unidos.

No deja de impresionar la variedad de temas cultivados por los miembros de la generación actual. Preferente atención merecen asimismo los escritores de la novela introspectiva (o más bien psicológica). Luis Oyarzun, joven autor ya conocido como poeta, dejó buena impresión con su primera novela titulada La infancia (1940). Consta de una serie de episodios de la vida del niño Eugenio. E1 novelista procura penetrar en el mundo complejo del niño, mundo lleno de imágenes misteriosas, de dudas y ensueños.

De mayor importancia son las obras de dos mujeres cuyo aporte a la novela introspectiva ha sido considerable. Chela Reyes, que se destaca principalmente en la poesía, dió pruebas de su versatilidad en 1951, con Tía Eulalia, novela en prosa poética en la que dos hermanas están perdidamente enamoradas del mismo hombre. Sin embargo, es María Luisa Bombal quien más se distingue en la novela de introspección. La amortajada, publicada en 1938, fué uno de los éxitos más notables de la última época novelística chilena. Su concepción es original y atrevida. Presenta a una mujer en su lecho de muerte, evocando los hechos pasados de su vida atormentada. Es una de las pocas novelas chilenas de esta época que han sido traducidas al inglés. ${ }^{5}$ Su segunda novela The House of Mist (1947) fué escrita en inglés, con la ayuda de su marido. En su obra María Luisa Bombal, escritora impresionista de fino temperamento, logra unir artísticamente la vida íntima de sus personajes con los fenómenos del mundo exterior.

Debemos finalmente llamar la atención sobre la novela urbana, cultivada con éxito considerable por dos autores relativamente nuevos. Joaquín Ortega Folch ganó el Premio Unico de Novela, en el certamen celebrado por la Sociedad de Escritores en el año 1950. 
La novela premiada fué Infierno gris, serie de frescos de la vida intima de santiaguinos de todas las clases sociales. El autor se esfuerza por probar dos afirmaciones hechas en el frontispicio; a saber: que "La ciudad es un antro de perdición" y que "El hombre es siempre un bruto contenido por el freno de la ley ... un asesino en potencia". No hay nada que redima a los personajes del Infierno gris, capaces sólo de engaños, seducciones, robos, crímenes y malas intenciones. El libro es de innegable valor, por el vigor del estilo y la excelencia del diálogo. Sin embargo, el afán del autor de pintarlo todo de un modo tan pesimista, perjudica hasta cierto punto su vocación artística.

Escritor de espíritu más ancho y perspectivas más amplias, es Nicomedes Guzmán, indudablemente el novelista más discutido de nuestra época. La aparición en 1938 de su primera novela, Los hombres obscuros, provocó una gran sensación literaria. Su segunda novela, titulada La sangre y la esperanza (1943), acusa un arte novelístico de mayor plenitud y madurez. Nicomedes Guzmán es el pintor por antonomasia del conventillo chileno. Nadie $-\mathrm{y}$ no hacemos excepción de Alberto Romero, J. S. González Vera y Manuel Rojas - ha pintado con tal maestría y con tanta simpatía la existencia escuálida de sus habitantes. A diferencia de tantos novelistas de tendencia naturalista, Guzmán sabe también pintar el lado agradable de la existencia del conventillo. No faltan bellos horizontes, hermosas puestas de sol y sentimientos tiernos, en las páginas del joven autor. Sus personajes nos parecen de carne y hueso. Se aprecia asimismo en Guzmán su estilo recio y al mismo tiempo poético, rico en metáforas ingeniosas. El defecto principal del novelista es su frecuente e innecesaria crudeza de lenguaje.

En conclusión, cabe subrayar que lo que une a los jóvenes novelistas y hace de ellos una verdadera generación, es su deseo de apoyarse en los aspectos múltiples de la realidad chilena. Este deseo se manifiesta en movimientos como el "Angurrientismo" y en las preocupaciones costumbristas y regionales. Los novelistas de la época actual se están dedicando a la creación de una tradición novelística genuinamente nacional. Quizás su mayor defecto es la estrechez de sus horizontes que no se extienden más allá de su patria, o dicho de otro modo, su falta de universalidad. Sin embargo, será intere- 
sante seguir el futuro desarrollo de este grupo de artistas jóvenes que, no obstante habernos brindado cuadros fieles e interesantes de la contemporaneidad chilena, todavía no han alcanzado su plena madurez literaria.

\author{
Jacob Ornstein, \\ Washington, D. C.
}

\title{
NOT A S
}

1 Santiago, Editorial Nascimento, 1949, p. 37.

2 Estudios sobre la literatura chilena, Santiago, Editorial Nascimento, vol. 3, p. 203.

3 Nueva historia de la literatura americana, Buenos Aires, Ed. Americalee, 1946, p. 428.

4 Santiago, ediciones Orbe, 1942, p. 469.

5 Traducción norteamericana: The Shrouded Woman, New York, Farrar, Straus and Co., 1948.

6 Consúltese también: Arturo Torres-Rioseco, La novela en la América Hispana, Berkeley, California, 1949, pp. 221-224; John A. Crow, "A Critical Appraisal of the Contemporary Spanish-American Novel", en Hispania, Wallinford, Connecticut, vol, xxxiv, núm. 2, mayo, 1951. 